This document is the accepted manuscript version of the following article:

Zenyuk, I. V., Lamibrac, A., Eller, J., Parkinson, D. Y., Marone, F., Büchi, F. N., \& Weber, A. Z. (2016). Investigating evaporation in gas diffusion layers for fuel cel1s with X-ray computed tomography. Journal of Physical Chemistry C, $120(50), 28701-28711$. https://doi .org/10.1021/acs.jpcc. 6b10658

\title{
Investigating Evaporation in Gas Diffusion Layers for Fuel Cells with X-ray Computed Tomography
}

Iryna V. Zenyuk ${ }^{1, *}$, Adrien Lamibrac ${ }^{2}$, Jens Eller², Dilworth Y. Parkinson ${ }^{5}$, Federica Marone ${ }^{3}$, Felix N. Büchi ${ }^{2}$, Adam Z. Weber ${ }^{4}$

${ }^{1}$ Department of Mechanical Engineering, Tufts University, Medford, MA 02155

${ }^{2}$ Electrochemistry Laboratory, ${ }^{3}$ Swiss Light Source, Paul Scherrer Institut, 5232 Villigen PSI, Switzerland

${ }^{4}$ Energy Storage and Distributed Resources Division, ${ }^{5}$ Advanced Light Source, Lawrence Berkeley National Laboratory, 1 Cyclotron Road, Berkleey CA 94720, USA

*Tel. number: 617-627-7956 Fax number: 617-627-3058 e-mail: Iryna.Zenyuk@tufts.edu

\section{Abstract}

Understanding evaporation in porous media and the associated water distribution for a given saturation is critical for optimizing many different technologies including polymer-electrolyte fuel cells. In these devices, heat and mass-transport are coupled due to the two-phase transport of water and operating temperatures from subzero to $80{ }^{\circ} \mathrm{C}$. Especially critical is understanding phase change in the mixed wettability, carbon gas-diffusion layers (GDLs). While previous works have measured evaporation rates empirically for a given saturation, there remains a need to explore the mechanisms governing evaporation, which are tied directly to the internal water distribution. In this paper, liquid-water evaporation rates in GDLs are measured in-situ using 
synchrotron X-ray computed tomography (CT). X-ray CT allows visualizing the evaporating water-front location and interfacial water/air surface area, thereby enabling true surface-area based evaporation rates. It is found that the overall specific evaporation rate is essentially constant as a function of saturation and that the water/air interfacial area scales almost linearly with saturation. To isolate transport and kinetic contributions to the overall evaporation rate, we systematically varied gas flowrate and composition. A three-dimensional mathematical model with direct meshes of liquid-water evaporation fronts from the X-ray CT studies allowed for the determination that the evaporation is transport limited. The overall results provides insight into evaporation phenomena in porous media.

\section{Introduction}

Effective liquid-water management is critical for polymer-electrolyte and alkaline-exchange membrane fuel cells, as well as other multiphase technologies. ${ }^{1}$ In the fuel cells, heat and mass transport are tightly coupled due to two-phase transport of water. ${ }^{2}$ At lower operating temperatures and during start-up, there is need to remove liquid water from the water-producing cathode to ensure adequate reactant delivery. ${ }^{3-4}$ At higher operating temperatures, thermal gradients in the system promote water removal in the vapor phase due to changes in water vapor pressure with temperature. ${ }^{5}$ To achieve maximum water permeation and consequently higher current densities, it is necessary to understand the interplay between pressure- and capillarydriven liquid-water transport and phase-change induced (PCI) flow ${ }^{6-7}$ due to evaporation/condensation in the porous electrodes and carbon backing layers called gas diffusion layers (GDLs). GDLs serve multifunctional roles, including electron and heat conduction,

reactant-gas delivery and water removal. These layers are thin (on the order of 100's of micrometers thick) typically non-woven carbon papers, having fiber diameters on the order of 
$10 \mu \mathrm{m}$ with a porosity range of 65 to $88 \% .^{8-10}$ To enhance their water-removal ability, they are normally treated with a hydrophobic agent (e.g. PTFE). Thus, these materials exhibit mixed wettability ${ }^{11}$ and have porosity profiles with an average pore size of tens of micrometers. Heat and mass transport in these layers depend on the GDL's morphology (porosity, tortuosity, and wettability) and material transport properties, such as electrical and thermal conductivity, gas diffusivity, and fluid permeability.

The temperature profile in the fuel cell is mainly due to the inefficient oxygen reduction reaction at the cathode, constituting close to $75 \%$ of total heat generated, ${ }^{1}$ and the coolant flow at the gas channel flowfield. PCI flow is water flow induced by evaporation at the hotter location and subsequent condensation along the path of decreasing temperature. Simultaneously, heat redistribution occurs due to the high heat of evaporation of water. Although the net heat due to condensation and evaporation is small relative to the reaction heat, when this net heat is separated into heat due to water evaporation and condensation, then it has been shown that each term is 2.5 times larger than the reaction heat. ${ }^{1}$ Thus, the heat transported with PCI flow is significant and needs a detailed investigation. Although water transport in GDLs has been investigated with modeling and experiments, ${ }^{12-15}$ evaporation kinetics and PCI flow are poorly understood, primarily due to a lack of fundamental insight caused by the challenge of experimental measurements and visualization of the evaporating water front and distribution within these porous materials.

Over the last few years there has been a significant progress in visualizing water distribution within the pores of the GDL using X-ray computed tomography (CT). ${ }^{14,16-22}$ This technique is non-destructive, has enough resolution to allow for visualization of three-dimensional GDL structures and water clusters within them, ${ }^{10,}{ }^{18,23}$ and works under ambient conditions. ${ }^{14}$ 
Moreover, synchrotron sources have short scan times to effectively capture transient conditions. Recent studies have shown that water occupies less than about $50 \%{ }^{24}$ of the GDL pore volume even at high liquid pressures because of the hydrophobic treatments, and capillary fingering is the predominant liquid-water transport regime in the absence of thermal gradients. ${ }^{14,25}$

Evaporation phenomena in porous fuel-cell components has not been visualized, although it has been investigated in terms of minimizing the amount of residual liquid water after fuel-cell shutdown. ${ }^{26-29}$ If this water remains inside the catalyst layer or the other components, it can be detrimental for fuel-cell performance and startup, especially also under subzero conditions. ${ }^{15,30-32}$ ${ }^{33}$ In the limited number of previous evaporation studies of GDLs, the evaporation rate was measured as a function of overall liquid-water saturation. ${ }^{29,}{ }^{34}$ These rates only resulted in empirical parameters and not significant insight into the mechanisms of evaporation. The evaporation rates were found to have a strong dependence on initial liquid-water content, thus it was not possible to deduce exact mechanisms for evaporative transport of water or any structure/function or master curve type relationships.

Macroscopic models describe the physics of evaporation in hydrophilic media with the funicular stage in which liquid capillary transport is dominant and the pendular stage where diffusive transport dominates. ${ }^{35}$ Pore-network models (PNMs) have also predicted an initial fast drying rate period for the water front followed by slower evaporation periods. The initial period is due to viscous water flow to the evaporating front, whereas the slow drying is due to evaporation of disconnected or residual water clusters. ${ }^{34,36-39}$ Overall, evaporation in hydrophobic media is not as well-studied as evaporation in hydrophilic porous media. For similar porousmedium morphologies using beads, the evaporation rate in hydrophobic media is an order of magnitude smaller than that in hydrophilic ones. ${ }^{40}$ Capillary liquid transport (the fast evaporation 
regime) is no longer fast due to higher resistance to liquid transport in hydrophobic media and the diffusive regime dominates.

In this work, we elucidate the rate-limiting step that dictates evaporative transport of water through the carbon-paper porous layers. Using simultaneous evaporation-rate measurements and water-front information with X-ray CT, true evaporation rates are measured. Further insights are gained through mathematical modeling of the transport mechanisms using directly meshed water fronts observed with X-ray CT. Furthermore, an idealized water-front geometry is studied to understand the impact of thickness, compression, tortuosity, temperature, and water-front location on the evaporation rate within the mixed wettability GDLs.

\section{Experimental Experimental Setup}

Figure 1a shows the sample holder, syringe pump, and water column that are used for evaporation-rate measurements and imaging. The set-up was originally developed for TOMCAT beamline at Swiss Light Source (SLS) and duplicated with modifications for Beamline 8.3.2 at Advanced Light Source (ALS). For the SLS setup, the GDL sample was sandwiched between two graphite endplates as shown by Figure 1b, where the bottom plate contained a $0.2 \mathrm{~mm}$ diameter hole for water injection and the top plate had a channel for gas flow. The GDL diameter was $5 \mathrm{~mm}$, and the channel dimensions were $3 \times 3.9 \mathrm{~mm}$; $60 \%$ of the GDL was exposed to the gas flow at $200 \mathrm{NmL} / \mathrm{min}$. Between the GDL and the bottom graphite plate a hydrophilic membrane (Millipore Durapore GVWP04700, thickness $125 \mu \mathrm{m}$ ) was placed for uniform liquidwater redistribution. A cartridge heater and thermocouple were embedded in the setup to allow precise temperature control using a controller. All the experiments reported here were conducted at $30^{\circ} \mathrm{C}$. 
For the ALS setup, a $3.2 \mathrm{~mm}$ diameter GDL was sandwiched between the hydrophilic plug (Whatman ${ }^{\mathrm{TM}}$ Cyclopore $^{\mathrm{R}}$ polycarbonate and polyester membrane, Pore Size: $0.2 \mu \mathrm{m}$ ) on top of an aluminum injection plate and hydrophobic plug (Whatman ${ }^{\mathrm{TM}}$ 7585-004 Grade WTP Plain White PTFE Membrane Filter, Pore Size: $0.5 \mu \mathrm{m}, 74 \%$ porosity) on the top, as shown by Figure 1c. The gas line was directly suspended $1 \mathrm{~mm}$ above the top of the hydrophobic plug and the gas flow impinged onto the plug at $30{ }^{\circ} \mathrm{C}$ with a flowrate of $600 \mathrm{NmL} / \mathrm{min}$. At the SLS, the measurements were taken for capillary pressures prior to water breakthrough, whereas at the ALS, higher capillary pressures and larger saturation values were possible due to the hydrophobic plug on top of the GDL acting as a capillary barrier. The sample holder was fixed to the rotation stage at the beamlines and connected with flexible tubing to a water column, and syringe pump that remained stationary and adjacent to the stage. The water column was connected to the water injection location at the bottom of the sample via water inside the tubing, where a three-way valve regulated the connections between syringe pump, water column, and the bottom of the sample. At first, water height in the column was set to a given liquid pressure, while the connection to the sample was open. Then, the connection to the syringe pump was closed and measurements of the evaporation rate began. The evaporation took place from the water front in the GDL over time. The evaporation rate was determined by either recording the time $\Delta \mathrm{t}$ for water column height to reduce by $1 \mathrm{~cm}(1 \mathrm{mbar})$ or noting change in water column height for a given time $\Delta \mathrm{t}$ (approximately $10 \mathrm{~min}$ ). Thereafter the water level was refilled to the state before evaporation measurement and the syringe pump was used to refill the evaporating water for the CT scan. 

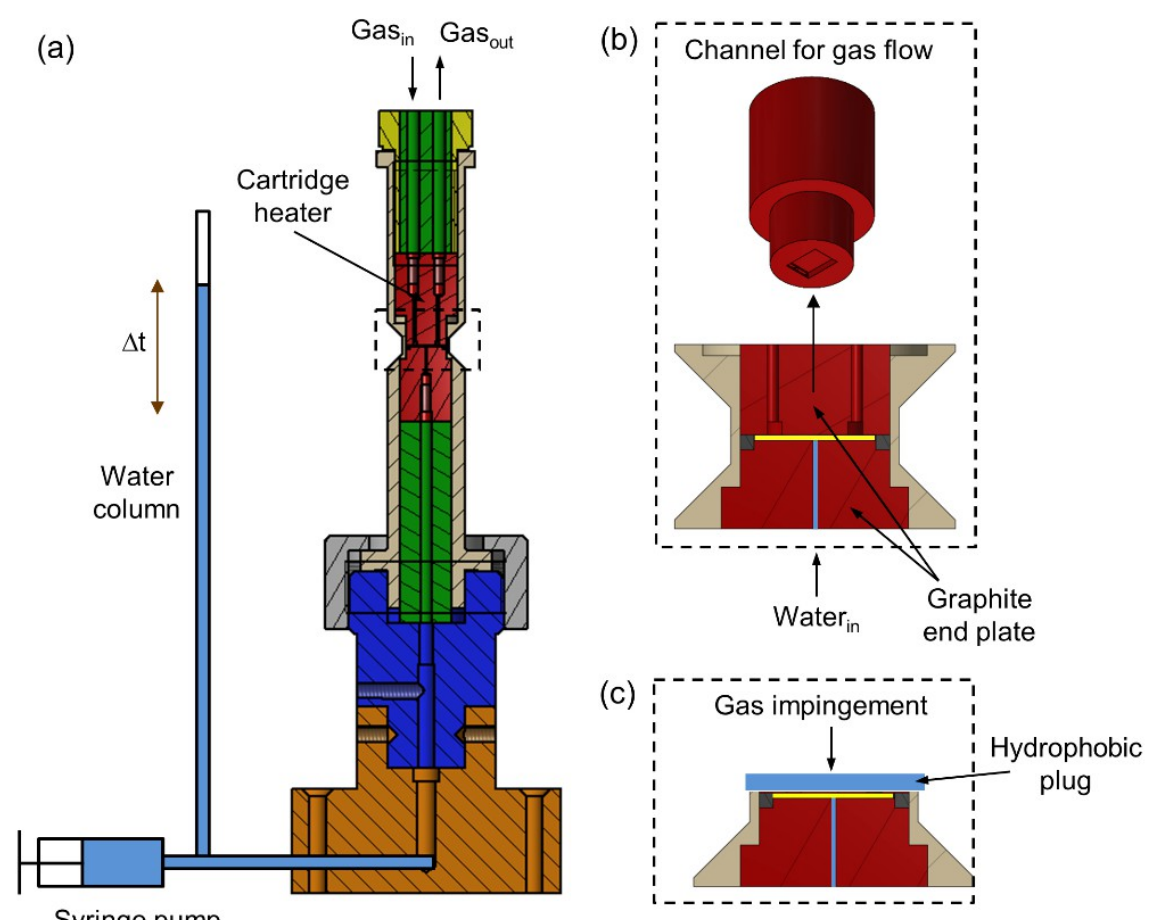

Syringe pump

Figure 1: a) Experimental setup at the beamline, b) schematic of a gas flow-channel for the setup at the SLS and c) gas impingement set-up with hydrophobic plug at the ALS.

\section{ALS}

The tomography experiments for the GDL characterization were conducted at Beamline 8.3.2 at the Advanced Light Source (ALS). A double-multilayer monochromator was used to select $22.5 \mathrm{keV}$ X-rays, and detection was with a $0.5 \mathrm{~mm}$ LuAG scintillator and 5x lenses with a sCMOS PCO.Dimax camera, giving a $2.2 \mu \mathrm{m}$ pixel dimension, and a $4.4 \mathrm{~mm}$ horizontal field of view (FOV). Using a $40 \mathrm{~ms}$ exposure time yielded 5500 counts on the camera. For each tomographic scan, 1025 projections were acquired over a $180^{\circ}$ rotation. The total scan time was approximately $5 \mathrm{~min}$. 
For X-ray tomographic microscopy imaging was performed at the TOMCAT beamline of the Swiss Light Source (SLS), a beam energy of $13.5 \mathrm{keV}$, exposure times of $15 \mathrm{~ms}$ per projection and 2001 projections per tomographic scan were used. With the PCO.edge 5.5 camera and the 24x zoom microscope used, a pixel edge length of $2.5 \mu \mathrm{m}$ was obtained. The entire sample did fit into the field of view and dark (no beam) and flat (no sample) images were taken for each scan to correct for lateral fluctuation of the beam intensity. The total scan-time was less than 1 min.

For the experiments at ALS and SLS the number of tomographic scans per sample was less than ten to limit the GDL exposure to radiation. With photon flux of $6 \times 10^{11}$ photons $/ \mathrm{s}^{1} \mathrm{~mm}^{2}$ at 13.5 $\mathrm{keV}$ with exposure time of $30 \mathrm{~s}$ a radiation damage is not expected to be significant for up to 10 20 scans per sample ${ }^{41-42}$. With lower photon flux $\left(\sim 2 \times 10^{11}\right.$ photons $\left./ \mathrm{s}^{1} \mathrm{~mm}^{2}\right)$ at ALS and higher energy of $22.5 \mathrm{keV}$, where the mass-attenuation coefficient for Teflon is reduced by a factor of 4 , lower radiation damage is expected for the same number of scans.

\section{Materials}

As reported in Table 1, two types of GDLs: SGL 24 BA and SGL 10 BA were used in this study. The testing conditions included either $\mathrm{N}_{2}$, or $\mathrm{He}\left(\mathrm{H}_{2}\right.$ at SLS) dry gas at various flowrates. The porosity values were calculated from thresholded image-stacks and the thickness was measured as an average of 5 measurements at different locations. For samples 2, 3, 5 and 7 two GDLs were stacked on top of each other and the thickness reported in Table 1 reflects the final combined thickness of two layers. 
Table 1. Materials used in experiment, testing conditions and materials’ properties.

\begin{tabular}{|c|c|c|c|c|c|}
\hline $\begin{array}{l}\text { Sample } \\
\text { number }\end{array}$ & Type & Testing conditions & $\begin{array}{l}\text { Liquid } \\
\text { Pressure } \\
\text { range } \\
\text { [mbar] }\end{array}$ & Porosity [-] & $\begin{array}{l}\text { Thickness } \\
(\sigma)[\mu \mathrm{m}]\end{array}$ \\
\hline $\mathrm{S} \# 1$ & SGL $10 \mathrm{BA}$ & $\begin{array}{l}\text { Hydrophilic/phobic plugs, impinging } \\
\text { flow, } 600 \mathrm{NmL} / \mathrm{min} \mathrm{N}_{2}\end{array}$ & $3.6-28$ & 0.71 & $433( \pm 22)$ \\
\hline $\mathrm{S} \# 2$ & SGL 10 BA & $\begin{array}{l}\text { Hydrophilic/phobic plugs, impinging } \\
\text { flow, } 600 \mathrm{NmL} / \mathrm{min} \mathrm{N}_{2}\end{array}$ & $10-33.7$ & 0.733 & $\begin{array}{l}823( \pm 48) \\
2 x\end{array}$ \\
\hline $\mathrm{S} \# 3$ & SGL 10 BA & $\begin{array}{l}\text { Hydrophilic/phobic plugs, impinging } \\
\text { flow, } 600 \mathrm{NmL} / \mathrm{min} \mathrm{He}\end{array}$ & $10-15$ & 0.71 & $\begin{array}{l}770( \pm 18), \\
2 x\end{array}$ \\
\hline $\mathrm{S} \# 4$ & SGL 24 BA & $\begin{array}{l}\text { Hydrophilic/phobic plugs, impinging } \\
\text { flow, } 600 \mathrm{NmL} / \mathrm{min} \mathrm{N}_{2}\end{array}$ & $5.2-20$ & 0.58 & $186( \pm 17)$ \\
\hline $\mathrm{S} \# 5$ & SGL 24 BA & $\begin{array}{l}\text { Hydrophilic/phobic plugs, impinging } \\
\text { flow, } 600 \mathrm{NmL} / \mathrm{min} \mathrm{N}_{2}\end{array}$ & $10-30$ & 0.67 & $\begin{array}{l}362( \pm 13) \\
2 x\end{array}$ \\
\hline $\mathrm{S} \# 6$ & SGL 24 BA & $\begin{array}{l}\text { Hydrophilic plug, channel geometry, } \\
200 \mathrm{NmL} / \mathrm{min} \mathrm{N}_{2}, \mathrm{H}_{2}\end{array}$ & $2-5$ & 0.55 & $164( \pm 15)$ \\
\hline $\mathrm{S} \# 7$ & SGL 24 BA & $\begin{array}{l}\text { Hydrophilic/phobic plugs, impinging } \\
\text { flow, } 600 \mathrm{NmL} / \mathrm{min} \mathrm{He}\end{array}$ & $10-17.5$ & 0.64 & $\begin{array}{l}353( \pm 24), \\
2 x\end{array}$ \\
\hline
\end{tabular}

\section{Image Reconstruction and Segmentation}

$A L S$ : Preprocessing of the acquired images was performed with Fiji/ImageJ, then phase retrieval was performed with the Modified Bronnikov Algorithm (MBA), and tomographic reconstruction (including a ring reduction filter) was performed using Octopus 8.6. ${ }^{43}$ Image segmentation and analysis was carried out with Fiji/ImageJ. Two phases were identified during segmentation: fiber and void space, and these were separated by thresholding, with the threshold determined by the Otsu algorithm.

SLS: From the XTM scan, gray scale 3D images of the samples are reconstructed using the gridrec reconstruction algorithm. ${ }^{44}$ For quantitative analysis, the images were segmented into the 
different phases (solid, liquid and void). The workflow used here has been previously described in detail, following the procedure of filtering, thresholding dry and wet images, subtraction, hole filling and recombination. ${ }^{45}$ As for the ALS workflow the porosity of the binder is not resolved and the binder thus considered as solid. Therefore reported porosities are lower than expected from the simple thickness-porosity relationship based on the data sheet porosities of the materials.

\section{Water Direct Meshing}

Thresholded image stacks of water were converted into binary STL files using BoneJ plugin within Fiji/ImageJ. The resampling factor of 4 was used and with a resolution of $2.2-2.5 \mu \mathrm{m}$, it translated to water fronts with a smoothing factor of about $8.8-10 \mu \mathrm{m}$. The fiber diameters are on the scale of $10 \mu \mathrm{m}$, thus having a water front with a unit size of $8.8-10 \mu \mathrm{m}$ is within the scales of the current methods. A sensitivity study for the resampling factor is shown in Supplementary Information (SI), where it is shown that for a resampling factor of 4 the error in water surface area computation is $<5 \%$. Gmsh, an open-source 3D finite element grid generator, was used to import STL geometries of water and to mesh them volumetrically. ${ }^{46}$ The volumetric mesh was optimized with 3D Netgen to ensure high mesh quality. From Gmsh, the volumetric mesh was saved as a NASTRAN file and imported into a computational Multiphysics software (Comsol Multiphysics 5.1), where the mesh served as both a physical domain and a meshed volume.

Water surface area was computed via surface integral from the generated mesh. Only surface area of the water front facing the GDL and pores was accounted for, the water surface area in contact with hydrophilic plug was not included in calculations. 


\section{Model Formulation}

Figure 2 shows modeling domains consisting of GDL ( $\Omega$ GDL) and liquid water $(\Omega L)$, where the GDL is represented with a volume-averaged approach, whereas the water domain is imported as a volumetric mesh and physical domain. The height of the domain $(\mathrm{z})$ is that of the GDL determined from imaging and reported in Table 1. Figure 2a also shows evaporation resistances due to interface kinetics, $R_{k}$, diffusion through the bulk of the GDL, $R_{\text {diff, }}$ and convection in the channel, $R_{\text {conv }}$. In the model the kinetic resistance is assumed negligible and the results are compared to the experimental data to check for the validity of this assumption. For the experiments with impinging flow onto the GDL, $R_{\text {conv }}$ was set to 0 , as we don't expect convection to be significant within the small pores of hydrophobic plug on top of the GDL. Below we discuss the governing equations and boundary conditions.

(a)

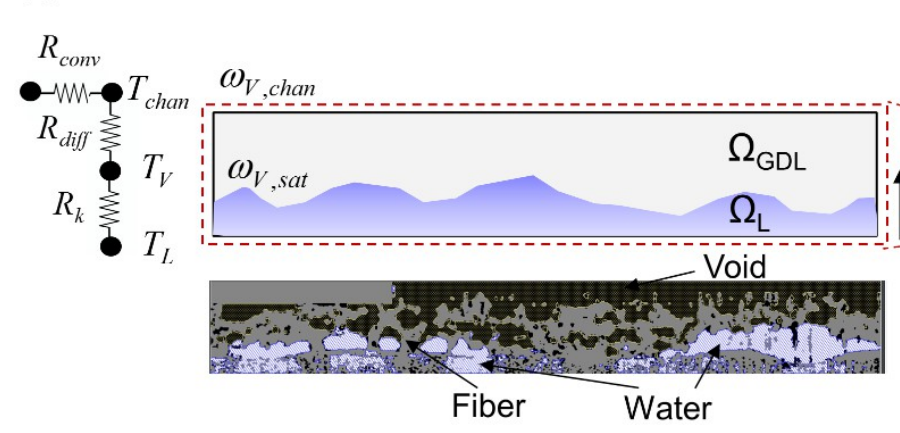

(b)

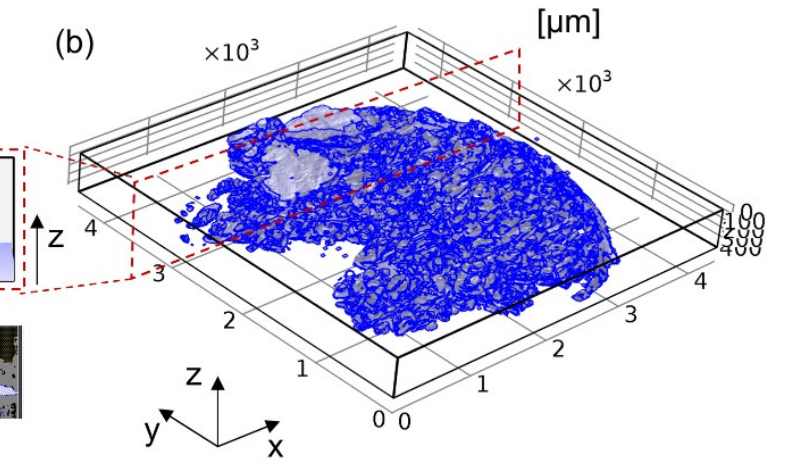

Figure 2: a) Two-dimensional schematic of modeling domains and equivalent resistor network, a cross-section tomograph with solid, void and water is also shown. b) Actual three-dimensional modeled domain with directly meshed water and macro-homogeneous GDL.

For the idealized water front simulations, water front was represented as a circular domain at the interface of the GDL and injection plate. For water front simulation descriptions of idealized water front as cylindrical domains refer to SI. 


\section{Governing equations}

The governing equations explain the physics of evaporation. Gas diffusion was described with

Stefan-Maxwell equation:

$$
\left.\frac{\partial\left(\rho_{G} \omega_{i}\right)}{\partial t}+\nabla \cdot \frac{B}{G}-\rho_{G} \omega_{i} \sum_{j}^{n} \bar{D}_{i j}^{e f f}\left(\nabla y_{j}+\left(y_{j}-\omega_{j}\right) \nabla P_{G} / P_{G}\right)\right]_{G}^{B}+\rho_{G} \omega_{i} \mathbf{v}_{G}=s_{v, w_{R}}+s_{r x n, w_{R}}
$$

The effective diffusion coefficient, $\bar{D}_{i j}^{\text {eff }}$, accounts for gas-species transport through the GDL,

which is porous and tortuous and is described as ${ }^{47}$

$$
\bar{D}_{i j}^{e f f}=\frac{\varepsilon_{G}}{\tau_{G}} \frac{p \bar{D}_{i j}}{P_{G}}
$$

where is tortuosity and $\tau_{\tau_{G}}$ is porosity of the GDLs. Because Eq. [1] is an inverted form of

Stefan-Maxwell equations, the binary diffusion coefficients, ${\overline{D_{i j}}}_{j}$, depend on mixture

composition and are related to the diffusion coefficients used in Stefan-Maxwell equations, $D_{i j}$ as reported previously. ${ }^{48}$ The diffusion coefficients temperature dependence is calculated as ${ }^{49}$

$$
\left.D_{\mathrm{H}_{2} O, N_{2}}=2.4 \frac{1}{\square} \frac{T}{285.8}\right]^{2.334}
$$




$$
\left.D_{\mathrm{H}_{2} \mathrm{O}, \mathrm{H}_{2}}=2.47 \frac{T}{\square 14682}\right]^{2.334}
$$

\section{Boundary conditions}

On the top of the GDL mass-fraction boundary conditions were set, where the mass fraction for

water vapor, $\omega_{V, \text { sat }}$ :

$$
\omega_{V, s a t}=\frac{y_{V}^{s a t} M_{V}}{y_{V}^{s a t} M_{V}+y_{D} M_{D}}
$$

where ${ }_{y}$ is the molar fraction of vapor (subscript ' $V$ ') or diluent (subscript ' $D$ '), M is the molar

mass of species,

$$
y_{V}^{\text {sat }}=\frac{P_{L}^{\text {sat }}}{P_{G}^{\text {in }}}
$$

$$
y_{D}=1-y_{V}^{s a t}
$$

where liquid water saturation pressure, ${ }_{P_{L}^{\text {sat }}}$, was computed as:

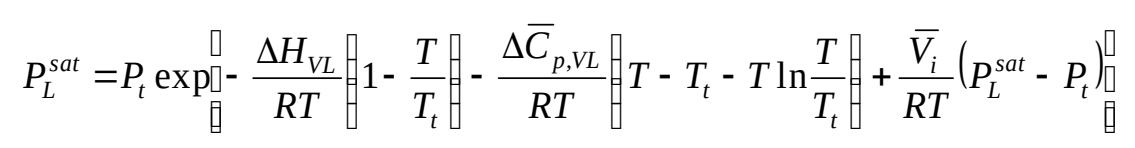


For the top of the water front, phase equilibrium between liquid and vapor is assumed with a relative humidity (RH) of 1 . The variables showing up in this equation are described in Table 2.

\section{Parameters and numerical method}

The finite-element simulations were performed using Comsol Multiphysics 5.1 (COMSOL, Inc.,

Burlington, MA). The geometric domain and mesh were imported from Gmsh as described above. Steady-state simulations were run and the evaporation flux was computed as a crosssection vapor flux leaving the top GDL boundary. From mass conservation, this is equal to the water flux leaving the top of the water front. The model parameters are reported in Table 2.

Table 2. Computational model parameters.

\begin{tabular}{|c|c|c|}
\hline Model Parameters & Value & Units \\
\hline Gas temperature, $\mathrm{T}$ & 303.16 & $\mathrm{~K}$ \\
\hline Gas pressure, $\mathrm{P}_{\mathrm{G}}$ & $1 \times 10^{5}$ & $\mathrm{~Pa}$ \\
\hline Triple point pressure, $\mathrm{P}_{\mathrm{t}}$ & 611 & $\mathrm{~Pa}$ \\
\hline Triple point temperature, $T_{t}$ & 273.16 & $\mathrm{~K}$ \\
\hline Difference in partial molar enthalpy between liquid water and vapor, $\Delta H_{V L}$ & -2500 & $\mathrm{~J} / \mathrm{g}$ \\
\hline $\begin{array}{l}\text { Difference in heat capacities between liquid water and vapor , } \\
\qquad \bar{C}_{p, V L}\end{array}$ & 2.36 & $\mathrm{~J} / \mathrm{gK}$ \\
\hline
\end{tabular}

\section{Results and Discussion}

In the following sections, we first discuss the water roughness factor (i.e., actual water surface area per geometric surface area), and then the evaporation results for different liquid pressure. Next, model and data comparisons are made. Finally, an idealized water front is explored with the model to quantify impact of various morphological and operation parameters on evaporation rate. It should be noted that throughout, the evaporation rate is presented as the specific evaporation rate (i.e., normalized per unit surface area of water), unless otherwise stated. 


\section{Roughness Factor}

Generally, the evaporation rate depends on a GDLs' morphological properties (i.e. porosity, tortuosity, thickness) and also operating conditions (i.e. temperature, $\mathrm{RH}$ ). Care has to be taken when comparing experimental or modeling data in the literature, as one or a number of these parameters can differ from study to study. From the experimental data, the maximum liquid-water saturation that was observed in these mixed-wettability GDLs was 0.4 for the case of a hydrophobic plug preventing water outflowing. Because of hydrophobic domains, water can form a uniform front at the injection plate|GDL interface and advances with capillary fingering ${ }^{43}$ while the hydrophobic plug contains water within the sample. Without hydrophobic plug water forms a uniform front at the interface of injection plate|GDL and then escapes to the channel via capillary fingering. For a stack of two GDLs, we observed water filling both at the injection plate|GDL interface but also the GDL|GDL interface; however, these two water fronts were connected only in few locations. Under fuel-cell operation, liquid-water saturations of 0.2 to 0.5 are observed. ${ }^{14,24,50}$ The present study captures a significant range of liquid saturations experienced during PEFC operation. It is of interest to know what is the roughness of water front area or what is the ratio of water surface area, $A_{w}$, to that of average cross-section area of the GDL, $A_{c}$,

$$
R F=\frac{A_{w}}{A_{c}}
$$

where $A_{w}$ is the surface area of evaporating water front. Table 3 presents all the values for the RFs for given saturations and liquid pressures. It also shows evaporation rates, and evaporation rates normalized per geometric area and surface area of water. 
Table 3. Properties for evaporating water front for the SGLs 10 BA and 24 BA.

\begin{tabular}{|c|c|c|c|c|c|c|c|c|}
\hline $\begin{array}{l}\text { Sample } \\
\text { number }\end{array}$ & $\mathrm{p}$ [mbar] & $\begin{array}{l}\mathrm{k}_{\text {evap }} \\
{[\mathrm{mol} / \mathrm{s}]} \\
\times 10^{-6}\end{array}$ & $\begin{array}{l}\mathrm{k}_{\text {evap }} \\
{\left[\mathrm{mol} / \mathrm{cm}^{2} / \mathrm{s}\right]} \\
\mathrm{x} 10^{-6}\end{array}$ & $\begin{array}{l}\mathrm{k}_{\text {evap }} \\
{\left[\mathrm{mol} / \mathrm{cm}^{2}{ }_{\mathrm{geo}} / \mathrm{s}\right]} \\
\mathrm{x} 10^{-6}\end{array}$ & $\begin{array}{l}\text { Water } \\
\text { Area }\left[\mathrm{m}^{2}\right] \\
\mathrm{x} 10^{-5}\end{array}$ & Saturation [-] & $\begin{array}{l}\text { Water } \\
\text { volume } \\
{\left[\mathrm{m}^{3}\right] \times 10^{-10}}\end{array}$ & $\begin{array}{l}\text { Water } \\
\text { RF }\end{array}$ \\
\hline S \#1 & 3.6 & 1.10 & 7.69 & 9.73 & 1.43 & 0.099 & 3.46 & 1.27 \\
\hline \multirow{7}{*}{$\mathrm{N}_{2}$} & 5.5 & 1.15 & 7.32 & 10.2 & 1.57 & 0.121 & 4.2 & 1.39 \\
\hline & 7.5 & 1.17 & 6.46 & 10.4 & 1.81 & 0.163 & 5.66 & 1.60 \\
\hline & 10 & 1.13 & 5.88 & .98 & 1.92 & 0.157 & 5.45 & 1.70 \\
\hline & 12 & 1.14 & 4.49 & 10.1 & 2.54 & 0.205 & 7.13 & 2.25 \\
\hline & 15 & 1.38 & 4.20 & 12.2 & 3.29 & 0.265 & 9.23 & 2.91 \\
\hline & 18 & 1.37 & 3.55 & 12.2 & 3.87 & 0.314 & 10.9 & 3.42 \\
\hline & 23 & 1.58 & 3.58 & 14 & 4.42 & 0.386 & 13.4 & 3.91 \\
\hline $\mathrm{S} \# 2$ & 10 & 1.09 & 10.8 & 9.62 & 1.01 & 0.027 & 1.85 & 0.89 \\
\hline \multirow[t]{3}{*}{$\mathrm{N}_{2}$} & 15 & 1.18 & 4.66 & 10.4 & 2.53 & 0.070 & 4.78 & 2.24 \\
\hline & 20 & 1.18 & 4.1 & 10.4 & 2.88 & 0.096 & 6.53 & 2.55 \\
\hline & 25 & 2.21 & 4.03 & 19.6 & 5.49 & 0.235 & 15.9 & 4.86 \\
\hline $\mathrm{S} \# 3$ & 10 & 1.56 & 118 & 13.8 & 0.132 & 0.003 & 0.194 & 0.12 \\
\hline $\mathrm{He}$ & 15 & 2.47 & 41.2 & 21.9 & 0.60 & 0.016 & 1 & 0.53 \\
\hline S \#4 & 5 & 0.956 & 6.41 & 8.46 & 1.49 & 0.156 & 1.88 & 1.32 \\
\hline \multirow[t]{3}{*}{$\mathrm{N}_{2}$} & 10 & 1.03 & 4.66 & 9.12 & 2.21 & 0.258 & 3.11 & 1.96 \\
\hline & 15 & 1.10 & 4.91 & 9.69 & 2.23 & 0.271 & 3.25 & 1.97 \\
\hline & 20 & 3.45 & 12.7 & 30.5 & 2.71 & 0.361 & 4.33 & 2.40 \\
\hline S \#5 & 12.5 & 0.698 & 97.1 & 6.18 & 0.0719 & 0.007 & 0.196 & 0.06 \\
\hline \multirow[t]{4}{*}{$\mathrm{N}_{2}$} & 15 & 0.750 & 24.2 & 6.64 & 0.310 & 0.022 & 0.596 & 0.27 \\
\hline & 17 & 0.746 & 20.3 & 6.60 & 0.367 & 0.029 & 0.799 & 0.32 \\
\hline & 22.5 & 0.742 & 11.8 & 6.57 & 0.629 & 0.055 & 1.52 & 0.56 \\
\hline & 30 & 2.43 & 10.6 & 21.5 & 2.30 & 0.179 & 4.91 & 2.04 \\
\hline S \#6 & 2 & 1.36 & 3.31 & 12.1 & 4.13 & 0.250 & 0.740 & 5.25 \\
\hline $\mathrm{N}_{2}$ & 5 & 2.07 & 4.75 & 18.3 & 4.35 & 0.270 & 0.810 & 5.54 \\
\hline $\mathrm{H}_{2}$ & 5 & 3.16 & 7.27 & 28 & 4.35 & 0.270 & - & - \\
\hline S \#7 & 10 & 1.72 & 21.6 & 15.2 & 0.798 & 0.053 & 1.35 & 0.71 \\
\hline \multirow[b]{3}{*}{$\mathrm{He}$} & 12.5 & 1.73 & 13.7 & 15.3 & 1.26 & 0.082 & 2.08 & 1.11 \\
\hline & 15 & 2.05 & 11.3 & 18.1 & 1.81 & 0.118 & 2.99 & 1.60 \\
\hline & 17.5 & 1.90 & 8.88 & 16.8 & 2.14 & 0.141 & 3.59 & 1.89 \\
\hline
\end{tabular}

Depending on local wettability and pore-sizes, the RF can vary for different GDL materials. A RF $<1$ indicates that surface area of water is smaller than the cross-section area of the GDL and this is because of discontinuous and small water clusters, which occurs at 
saturations of 0.08 or lower as shown by Figure 3a. The RF increases approximately linear with saturation, meaning that the surface of the liquid water increases also approximately with saturation. It is furthermore indicative that the water front forms occlusions or fingering as it advances, consistent with previous visualizations and PNMs. If the water front during water injection or generation would advance as a uniform front, then we would expect the RF to be constant, as only the top of the water front - locations of evaporation, contributes to the RF calculation. Particularly, larger isolated regions, formed by capillary fingering contribute largely to the RF as shown by Figure 3b (top) where the red line outlines the water clusters that contribute to the RF calculation. For thinner layers, the water front was more uniform (as there was no significant porosity increase in the middle of the layer's thickness) and resulted in lower RFs as shown by Figure 3b (bottom). The RF is similar for SGL 10BA and 24BA GDLs, as reported in Figure 3a and Table 3, even though their intrinsic morphologies differ to a certain extent $\mathrm{t}^{10}$. 


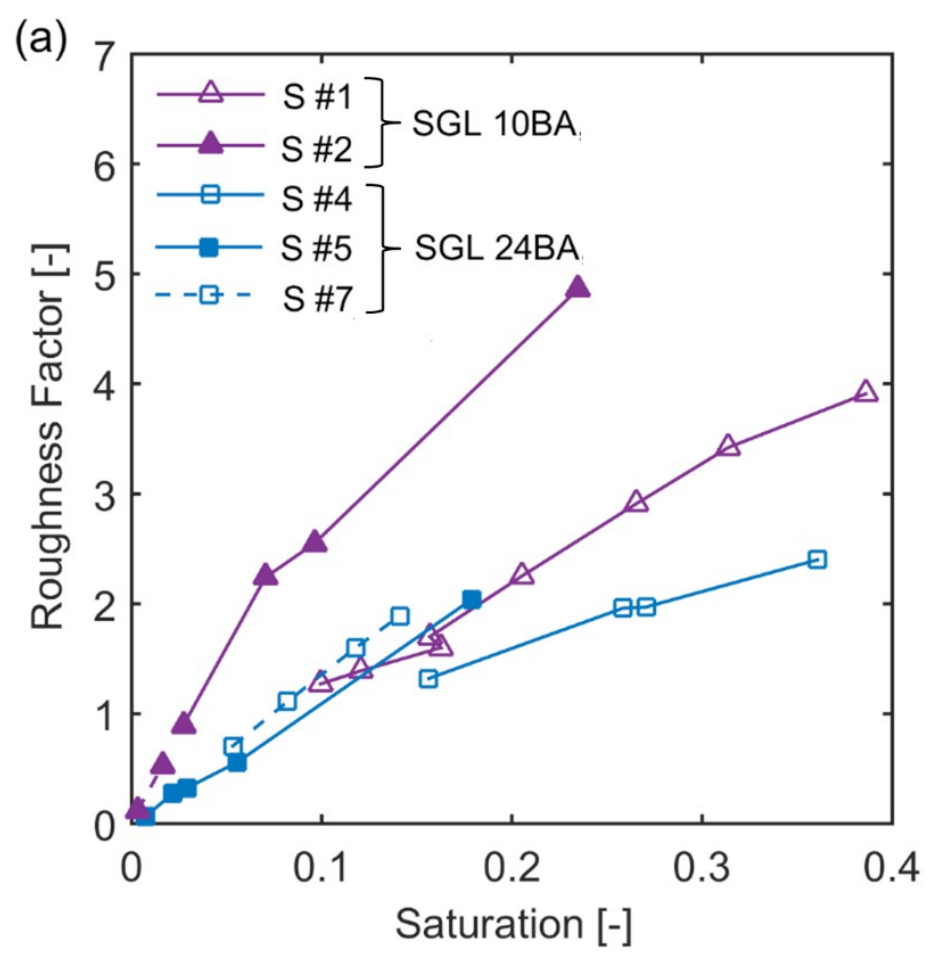

SGL 10BAS \#2, $S_{L}=0.23, R F=4.9$

(b)

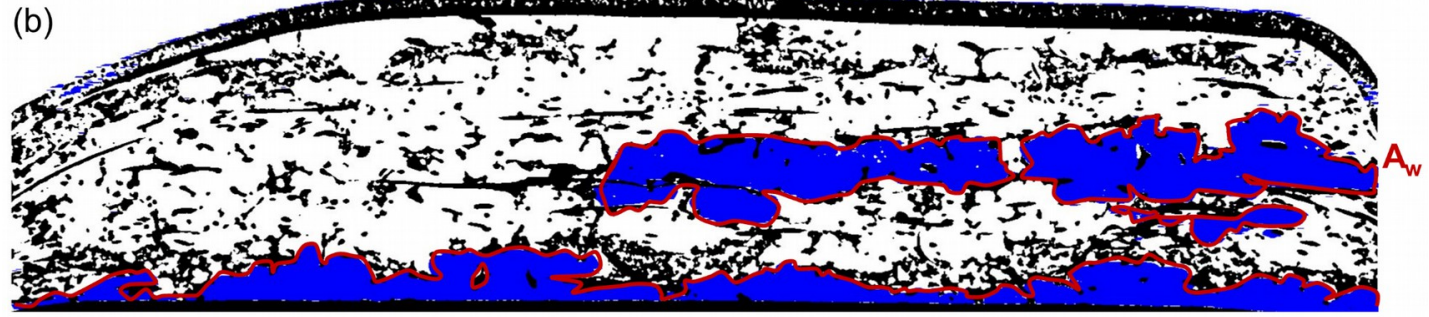

$\mathrm{A}_{\mathrm{c}}$

SGL 24BA S \#4, $S_{L}=0.36, R F=2.4$

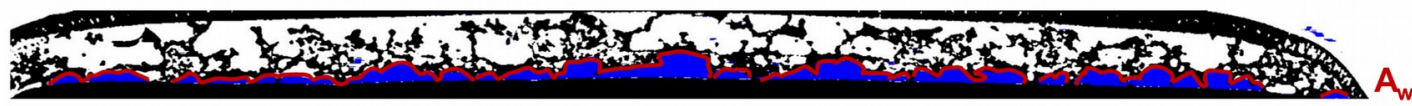

$500 \mu \mathrm{m}$

Figure 3: a) Water roughness factor as a function of saturation for SGL 10BA and SGL 24BA. b)

$$
\text { Examples of obtained } \mathrm{A}_{\mathrm{w}} \text { and } \mathrm{A}_{\mathrm{c}} \text {. }
$$

Error: Reference source not found shows an example of three-dimensional water-front penetration into the porous GDL under increasing liquid pressure. At low saturation (0.1) the 
water-front forms at the interface of the injection plate and the GDL. Under higher liquid pressures the water-front advanced into the GDL in a non-uniform manner, forming local occlusions and was advanced in certain locations further than in the others (saturation of 0.26 ) due to capillary fingering.

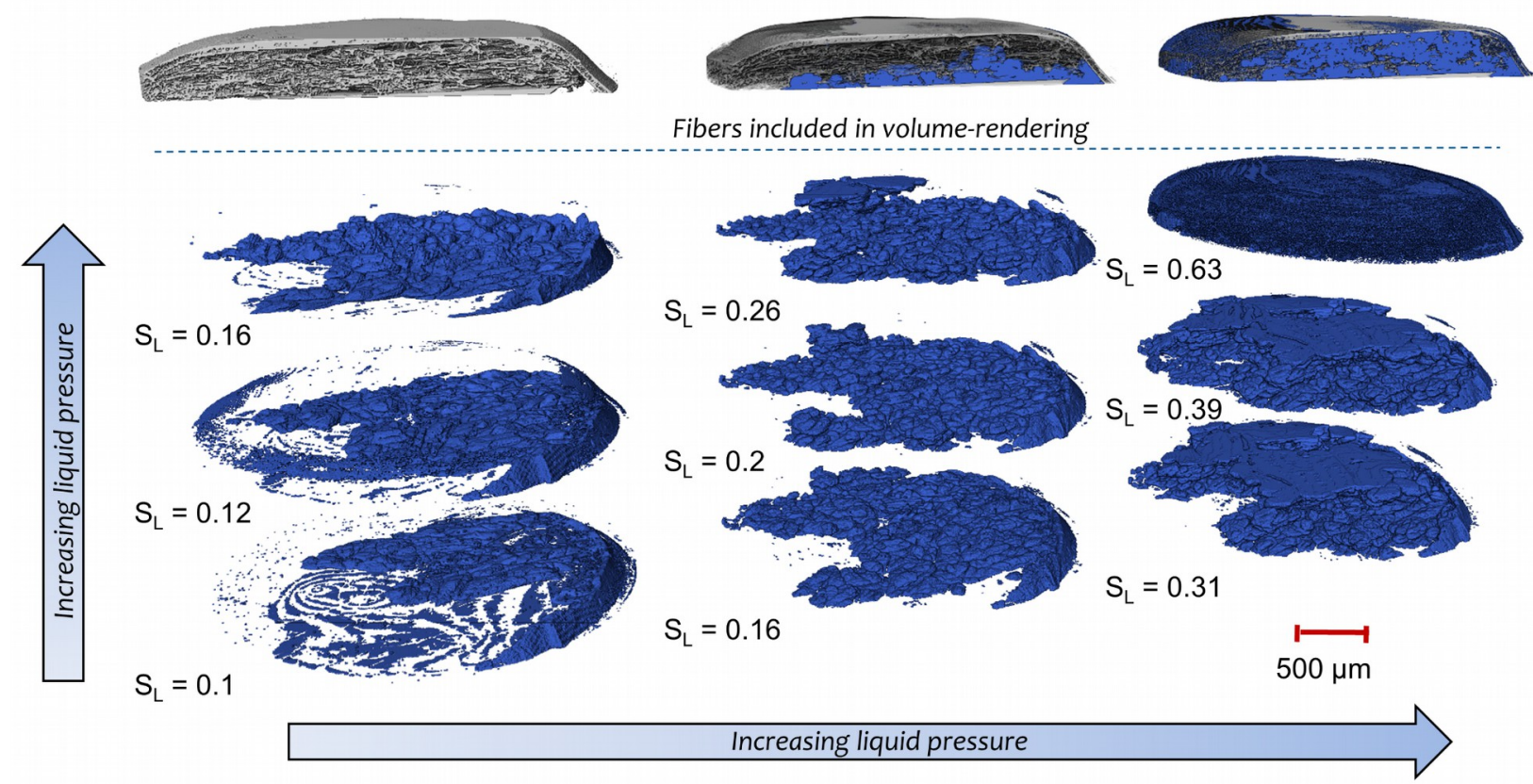

Figure 4: Volume-rendered water-front for S \#1, SGL 10BA for different liquid-water saturations, where top images include volume-rendering of carbon fibers.

\section{Evaporation Rate}

The evaporation rates for the SGL 24 BA (S \#4, 5, 6) and SGL 10 BA (S \#1) with properties reported in Table 1 are shown in Figure $5 \mathrm{a}$ and $\mathrm{b}$ as a function of RF and liquid water saturation, respectively. The high evaporation rate at low liquid pressure is due to very small water surface area and hence high local water vapor flux. From Figure 5b, it is observed that 0.1 liquid water saturation is sufficient to have the evaporation-rate scaling with the water surface 
area. Below this value, the evaporation rate per surface area of water is increasing with decreasing water surface area due to high local fluxes and more distributed water. At low saturation evaporation from water within hydrophilic membrane at the GDL/injection plate interface can contribute to the total rate and its significance will be assessed with the further studies. Model results are within the same order of magnitude as experiments and agree with the

experimental trends well. The evaporation rate asymptotes to a value around $\mathrm{mol} / \mathrm{cm}^{2} \mathrm{~s}$ for SGL 24BA, which is larger than the evaporation rate for thicker SGL 10BA. The model agreement with the results indicates that assuming local equilibrium and thus fast evaporation kinetics from the water front fits the data well; thus the evaporation is diffusion limited. Figure 5c and d show water front and three-dimensional model evaporation results for S \#4 and S \#5, respectively. For the water fronts represented by Figure 5d, the liquid water saturation is below 0.1 and hence the evaporation rate per unit surface area of water is higher: $9.8 \times 10^{-5} \mathrm{~mol} / \mathrm{cm}^{2} \mathrm{~s}$ for a saturation of 0.0072 and $2 \times 10^{-5} \mathrm{~mol} / \mathrm{cm}^{2} \mathrm{~s}$ for a saturation of 0.05 . Figure 5e shows the grey-scale and thresholded cross-section tomographs for the GDLs with water and fibers, where it is observed that unlike with SGL $10 \mathrm{BA}$, most of the water front is observed at the interface between the GDL and injection plate.

The evaporation rates for the set-up with dry gas flowing through the channel vs. impingement dry gas flow on the top of the sample demonstrated similar evaporation rates. S \#4 and S \#6 had similar porosities (0.55 vs. 0.58) and thicknesses (184 vs $164 \mu \mathrm{m}$ ) with the main 
difference being the way the dry gas was delivered (via channel for S \#6 and impinging flow for $\mathrm{S}$ \#4). For a saturation of 0.25 , the evaporation rates for both GDLs are around $0.5 \times 10^{-5}$ $\mathrm{mol} / \mathrm{cm}^{2} \mathrm{~s}$. Both experimental setup predictions are in good agreement over the measured evaporation rates.
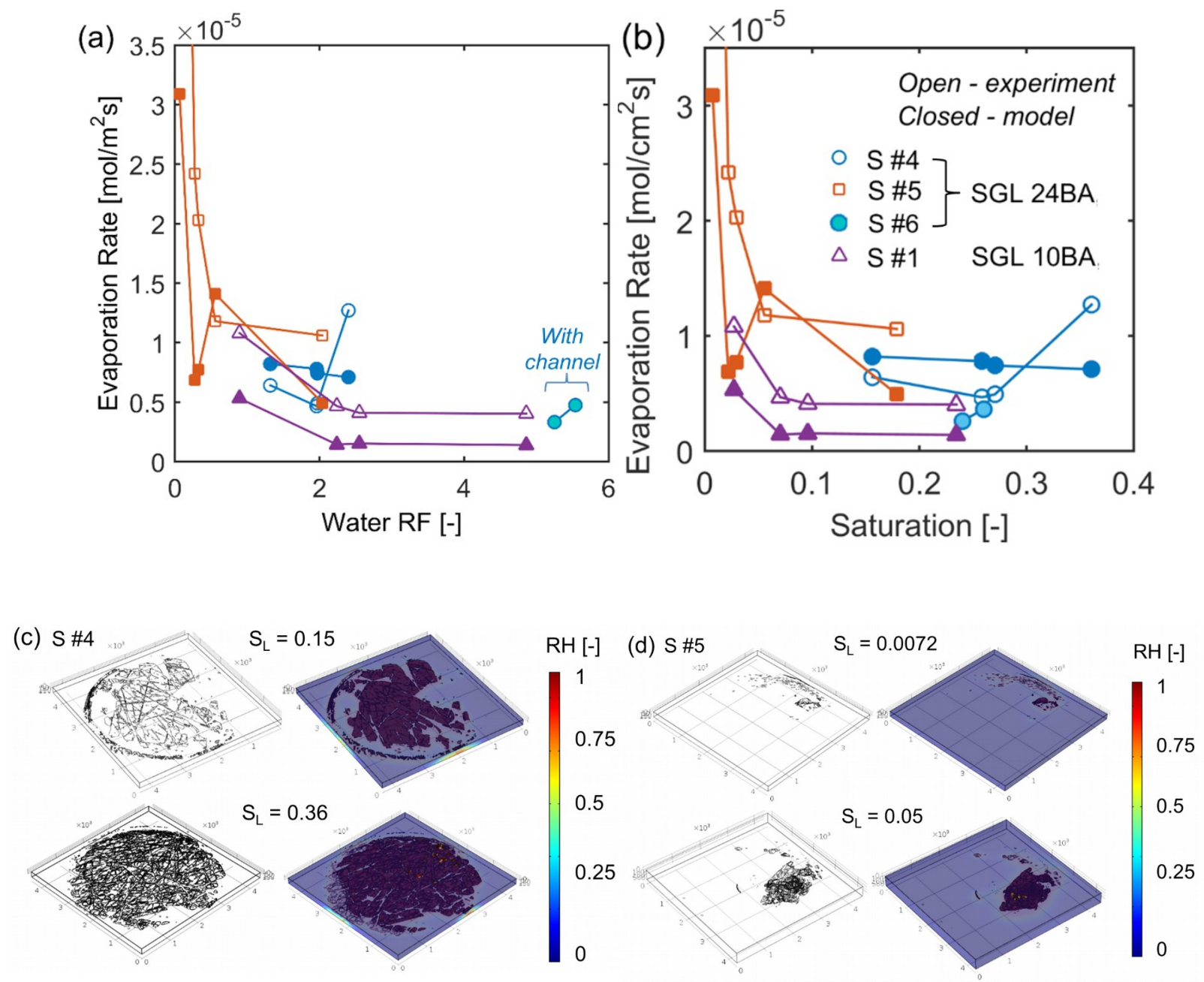

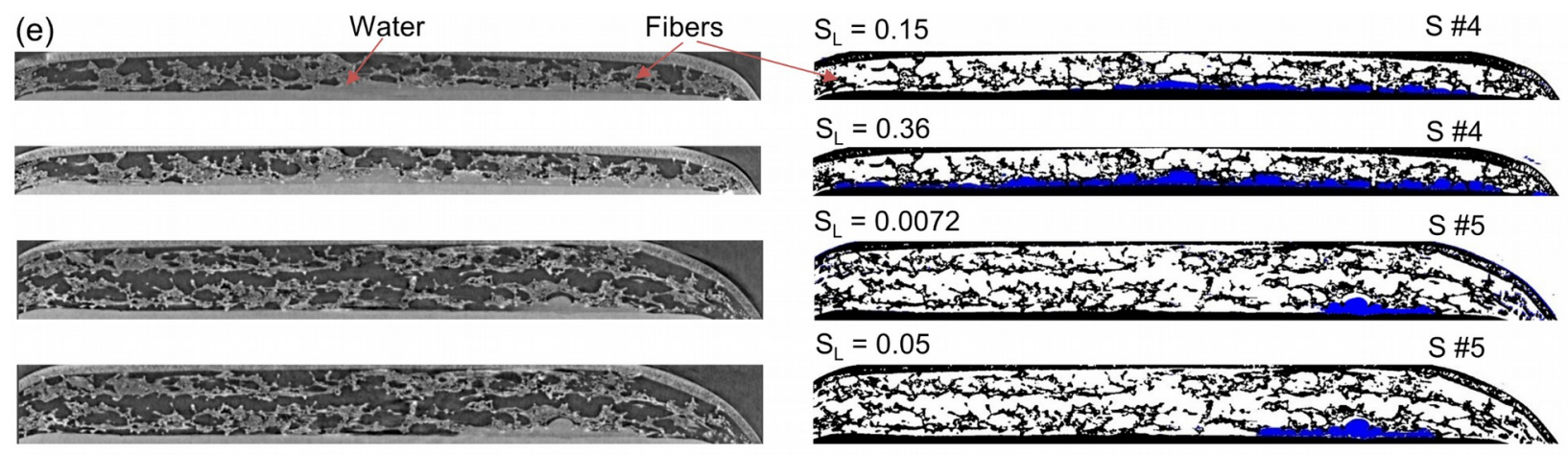

Figure 5: Evaporation rate normalized per surface area of water as a function of a) the water RF and b) saturation. Volumetric mesh of water front for c) SGL 24BA, S \#4 and d) SGL 24BA, S \#5 for two levels of water saturation. e) Cross-section raw gray scale data (left) and thresholded (right) tomographs of water fronts for S \#4 and S \#5.

As two cases were studied, with and without hydrophobic plug at the surface, the effect of the hydrophobic plug on the evaporation rate is studied via computational modeling, where idealized water fronts within mathematical domains of the GDL with and without hydrophobic plug are simulated. For thicker $(>200 \mu \mathrm{m})$ lower porosity GDLs $(<0.7)$ the hydrophobic plug introduces a small effect (less than $8 \%$ error in measurements). However, for thinner and more porous GDLs the error approaches 18\%. The hydrophobic plug can also corrupt measurements when the water front is close to it $(<50 \mu \mathrm{m})$ resulting in errors as high as $40 \%$. The details of the simulation and results are provided in SI.

\section{Nitrogen vs. Helium}

To quantify the role of diffusion through porous media better, the evaporation rates using

$\mathrm{N}_{2}$ and He are compared. These gases approximate quite well the evaporation conditions in a PEFC at the cathode and anode, respectively, as air is well-approximated with $\mathrm{N}_{2}$ and $\mathrm{H}_{2}$ with He. He is a lighter gas than $\mathrm{N}_{2}$ and therefore diffusion of water vapor in He is faster and from the 
modeling calculations the increase of a factor of 2.6 - 4 in evaporation flux is expected, depending on molar-mass dependency used for a diffusion coefficient ${ }^{47-49}$. Figure $6 \mathrm{a}$ and b show evaporation rate for SGL 10BA and SGL 24 BA as a function of RF and saturation, respectively.

The model predicts high evaporation rates of $4.12 \times 10^{-5}$ $\mathrm{mol} / \mathrm{cm}^{2} \mathrm{~s}$ for vapor transported through SGL 10BA in He (S \#3), for saturations below 0.1, whereas for vapor transport in $\mathrm{N}_{2}$ through SGL 10BA (S \#2) the evaporation is 4 times slower. This is in good agreement with theoretical predictions indicating that the evaporation rate is diffusion limited. Comparing the evaporation rates for SGL 24 BA (S \#4 and S \#7) for RF < 2, ratios of 2 to 3 are observed that are close to being within the range of predicted ratio of $2.6-4$.

For a PEFC the following implication can be drawn: for the same temperature in anode and cathode the evaporation rate in anode should be 2.6 - 4 times larger than that in cathode. In practice, anode side of the fuel cell is generally at somewhat lower temperatures because the heat due to ORR is much larger than that due to hydrogen oxidation reaction. For lower operating temperatures, it is beneficial to drive water through the anode as it has higher evaporation rate and also will not obstruct oxygen delivery pathways to the cathode electrocatalyst. For high temperatures $\left(>50^{\circ} \mathrm{C}\right.$ ), the evaporation rates in anode might be lower due to lower temperature in anode. However, as the PEFC components are thin with reasonable thermal conductivity then still water evaporation in the anode is higher. 

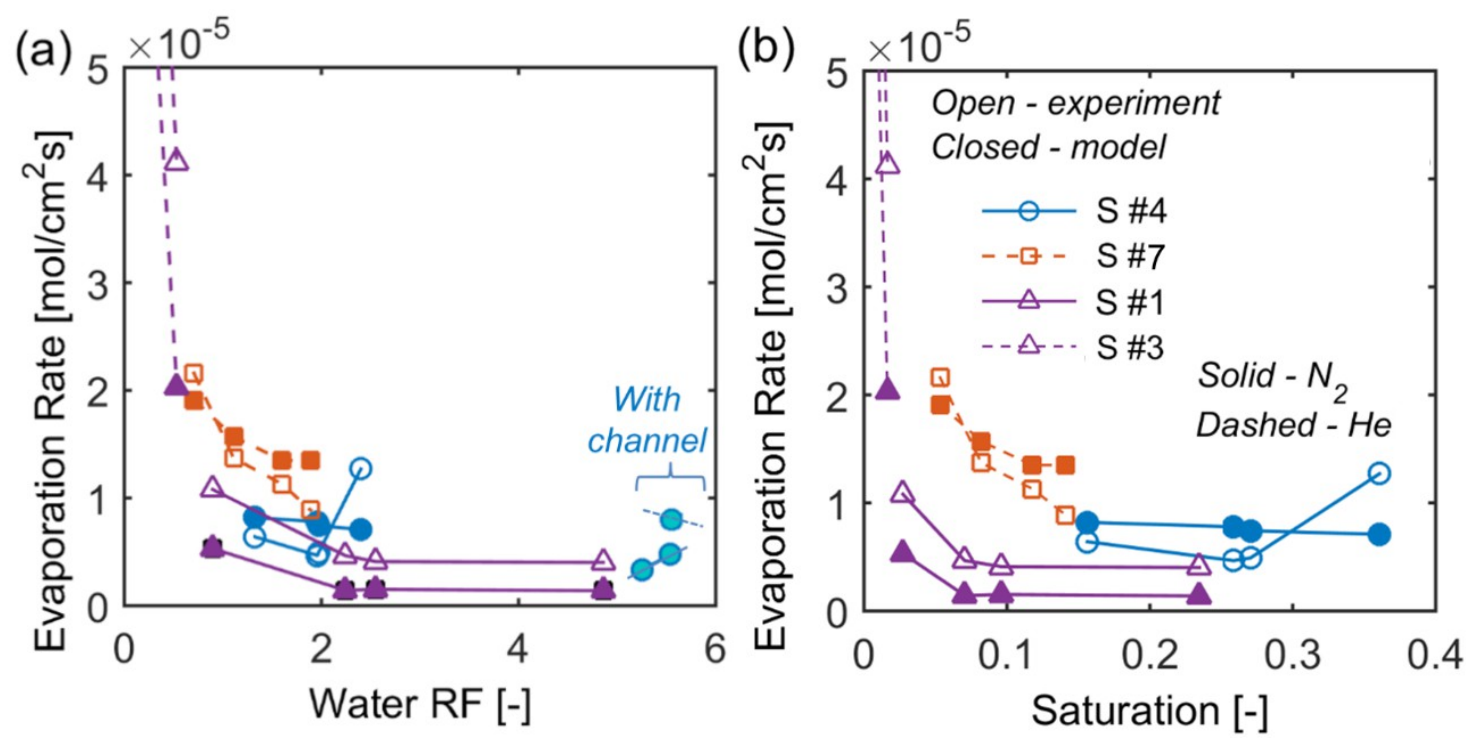

Figure 6: Evaporation rate normalized per surface area of water for $\mathrm{N}_{2}$ and He as a function of a) RF and b) saturation for SGL 10BA and SGL 24BA.

\section{Idealized Water Front}

To explore in more depth the impacts of various parameters, simulations were run using idealized water geometries. Figure 7a shows the dependence of the evaporation rate on water RF for a representative SGL 10BA with varying porosity. The thickness of the domain is $433 \mu \mathrm{m}$, with a porosity exponent, $\mathrm{m}$, of 2.8 (the exponent is for Eq. [2], where the porosity is cast as

$$
\begin{aligned}
& \text { ) and temperature of } 40{ }^{\circ} \mathrm{C} \text {. For high surface areas or high RFs, the evaporation rates } \\
& \frac{\varepsilon_{G}}{\tau_{G}}=\varepsilon_{G}^{m}
\end{aligned}
$$

start to asymptote to a constant value - similar to the observed experimental data. Porosity has a significant impact on the evaporation rates, as the rate decreases from 1.35 to $0.6 \mathrm{~mol} / \mathrm{cm}^{2} \mathrm{~s}$ as porosity decreases from 0.8 to 0.6. For stacked GDLs, the evaporation rate decreases even further. Stacking two GDLs results in increased diffusion distance and is equivalent to a porosity 
reduction of a single layer by $20 \%$ as shown in Figure $7 a$.

Similar effects were observed for changing tortuosity of the GDL as shown in Figure 7b, for a $433 \mu \mathrm{m} \mathrm{GDL}$ at $40{ }^{\circ} \mathrm{C}$ and porosity of 0.71 . From these simulations, it is apparent that increasing porosity exponent by 1 (increasing tortuosity) is equivalent to reducing porosity by $10 \%$. We also investigated the temperature dependence of the evaporation rate as shown by Figure 7c. The evaporation rate nonlinearly increases with increase in temperature because the diffusion coefficient of water vapor in nitrogen is higher at higher temperatures. For example, for water RF of 0.65 , the evaporation rate increased from 0.25 to $1.6 \mathrm{~mol} / \mathrm{cm}^{2} \mathrm{~s}$ (a factor of 6.4 ) as temperature increased from 20 to $50{ }^{\circ} \mathrm{C}$. Moreover, for the same temperature, the evaporation rate difference between low and high surface areas of water was much greater at higher temperatures (a factor of 5). At higher temperatures, the evaporation rates are higher and hence for the same small area of water, the local flux will be much higher.

Figure 7d shows the evaporation rate for the gas in the channel having various degrees of relative humidity $(\mathrm{RH})$ at three different temperatures. The evaporation is a linear function of $\mathrm{RH}$, however, the slopes are different for the evaporation rate vs. $\mathrm{RH}$ for the three different temperatures. At high temperatures, the evaporation rate changes the most with $\mathrm{RH}$ because the diffusion coefficient for vapor in $\mathrm{N}_{2}$ is highest. As the gas in the channel on the top of the GDL saturates, the evaporation rate decreases to 0 . For example, an order of magnitude decrease in the evaporation rate at $30{ }^{\circ} \mathrm{C}$ is observed when the channel $\mathrm{RH}$ increases from 0 to 0.9 . Studies of idealized water front modeled as cylinders of various height and surface area are presented in SI. The idealized water front model with water geometry modeled as cylinders (see SI) was conducted to further the understanding of evaporation rate scaling with saturation, RF and water front location. Evaporation rate per surface area of water front remained approximately constant 
for the same height of water front and varied saturations, what once again, confirmed the diffusion limitations of evaporation rate.
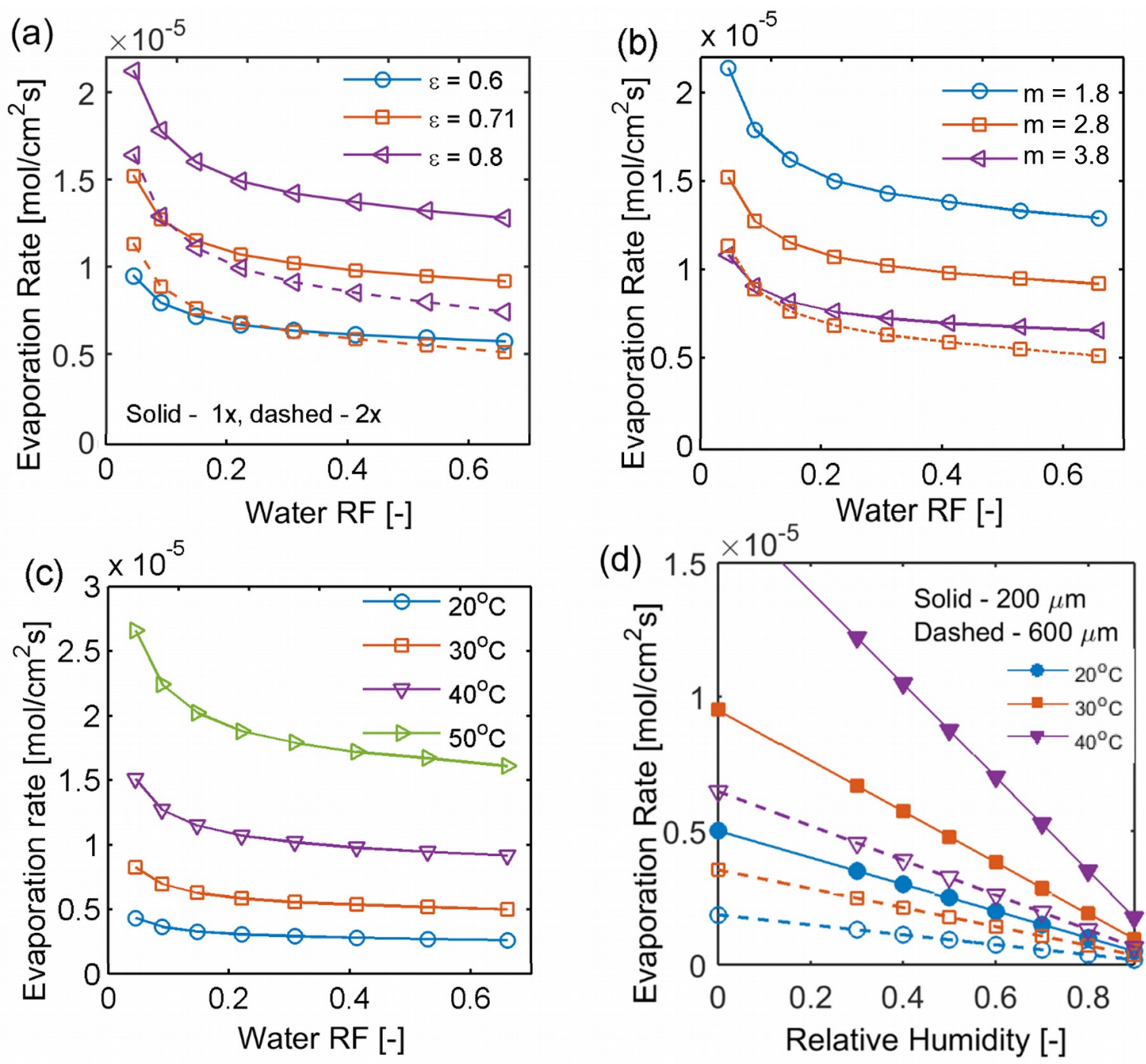

Figure 7: Evaporation rate normalized per surface area of water as a function of water RF for idealized water front when varying a) porosity, b) tortuosity, and c) temperature, d) evaporation rate as a function of relative humidity.

\section{Discussion and Implications}


Several studies observed a water removal rate increase due to evaporation with increase in GDL water saturation. ${ }^{29,34}$ These studies have identified three regions: falling-rate evaporation period (FRP), constant-rate evaporation period (CRP), and surface-evaporation regime (SER), which are generally present for hydrophilic media. In the current study, a water reservoir was connected to the water front on the bottom surface in order to simulate real-world operating conditions. This setup differs from that of Cho and $\mathrm{Mench}^{29,34}$, who presaturated GDLs with water and observed complete dryout after a prolonged purge time in order to simulate fuel-cell shut-down conditions.

At high saturations, the water front is far advanced into the GDL and the diffusion distance is reduced, hence the overall evaporation rate is high. This trend is in agreement with the FRP region identified previously. In the GDLs, CRP is due to the evaporating front receding as it evaporates; however, it evaporates in a nonuniform manner, and the higher exposed areas are compensated by the larger diffusion distances. Hence, the evaporation rate per surface area of water remains about constant. The data herein indicates that generally, evaporation in GDLs can be thought of evaporation of a water film with an additional diffusion barrier.

Comparing the present results to the study of Dae Hyun Kim et al. ${ }^{51}$ of water evaporation in wettable and water-repellent sands, our study suggests that water evaporation in GDLs is analogous to that in water-repellent sands. As the water front receded for wettable sands, hydraulically connected regions maintained their shape due to capillary transport and the evaporation front showed high degrees of roughness with all of the disconnected water clusters. However, the hydrophobic water-repellent sand showed a very uniform receding front with degrees of roughness comparable to this study. When a column of hydrophilic sand was connected to a hydrophobic one on one side, the combined column adopted the behavior of the 
hydrophobic medium: the evaporation front was very uniform with low degree of roughness. Although GDLs have local hydrophilic and hydrophobic regions on a smaller scale, our findings confirm the observation: for mixed wettability GDLs the evaporating front has a physical behavior similar to the hydrophobic domain.

The shapes of the observed evaporation curves did not represent regions of constant evaporation followed by region of SER, granted the saturations were not higher than 0.5 . Figure 8 shows a comparison of evaporative water-removal rates for normalized rates with geometric area vs. actual water front area for several samples. When normalizing per geometric area, a constant evaporation rate at lower saturation and rapid increase with increasing in saturation is observed, similar to that shown previously. ${ }^{29}{ }^{34}$ However, these trends are not representative of actual physics as the evaporation rate per unit area of water front remains constant at higher saturations.

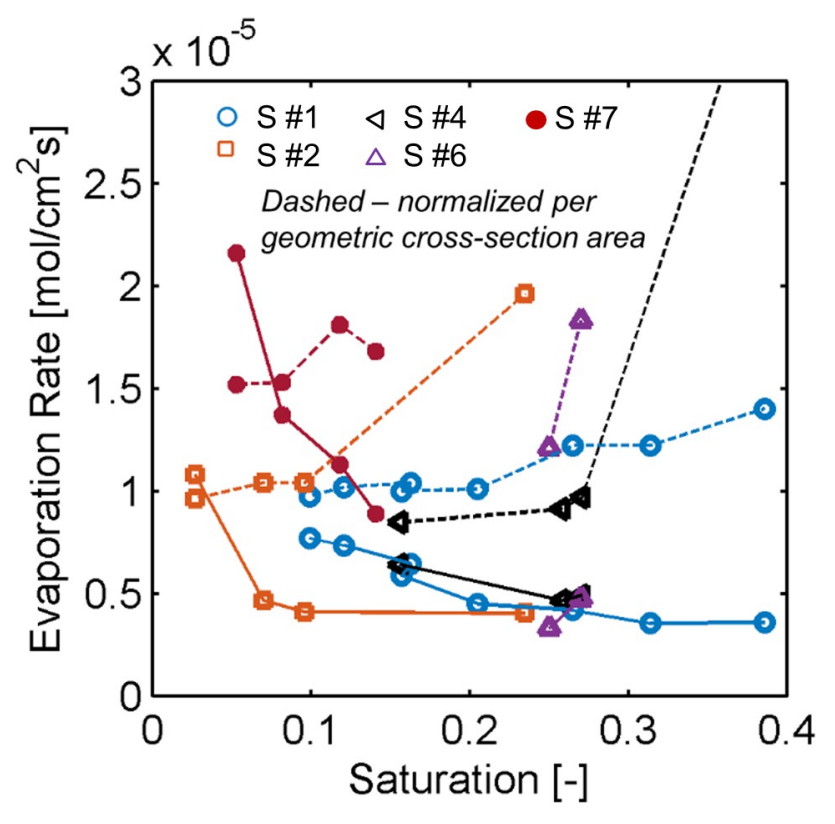

Figure 8 Comparison of evaporation rates as normalized per actual surface area of water and per 
geometric (dashed).

\section{Summary}

$\mathrm{X}$-ray computed tomography (CT) was used to visualize the evaporating water front in heterogeneous porous gas-diffusion layers (GDLs). At low liquid pressures and saturations lower than 0.1 , the evaporation rate per surface area of water front was high; however, as saturation increased past 0.1 and a connected water front was formed, the evaporation rates scaled well with the surface area of water. The thinner SGL 24 BA showed on average a higher evaporation rate than thicker SGL 10 BA GDLs, indication diffusion limitation.

Similar results for evaporation rates were obtained at two beamlines with slightly different sample holders, indicating data reproducibility across the laboratories. A model was constructed using directly meshed water fronts that accounts only for diffusion limitations and not evaporation kinetics (i.e., assumed local equilibrium). For most of the experimental data studied, the model showed reasonably good agreement, supporting the fact that the evaporation rate is diffusion limited. Further evidence was that the evaporation rate in helium was, on average, a factor of 2 to 4 greater than in nitrogen, as more-or-less expected depending on the molar-mass dependence of the diffusivities. From the X-ray CT data, a roughness factor (RF), defined as the water/air surface area per geometric area, for the water phase was determined. For saturations between 0 to 0.4 , the RF increased in a mainly linear manner and reached a maximum value of 5 . Normalizing the measured evaporation rate by the RF, resulted in a leveling off of the evaporation rate. This is consistent with a water front and evaporation that is transport limited. The RF value can be implemented in multiphysics simulations to account correctly for the physics of evaporation. This is the first study to normalize evaporation rate by actual surface area 
of water obtained with X-ray CT instead of cross-section area of the GDL. Overall, the findings and analysis help to elucidate the governing evaporation mechanisms and values in mixed wettability heterogeneous porous media.

\section{Supporting Information Description}

The supporting information section contains the following: effect of water surface area parsing, effect of hydrophobic plug on evaporation measurements, evaporation rate for $\mathrm{S} \# 1$, evaporation rate for various flow-rates for sample holder with channel, evaporation rate for idealized water fronts, evaporation rate theory overview.

\section{Acknowledgements}

We thank Prof. Jeff Gostick for insightful discussions. This work was funded under the Fuel Cell Performance and Durability Consortium (FC PAD) funded by the Energy Efficiency and Renewable Energy, Fuel Cell Technologies Office, of the U. S. Department of Energy under contract number DE-AC02-05CH11231, Program Development Managers Dimitrios Papageorgopoulos and Greg Kleen. The Advanced Light Source is supported by the Director, Office of Science, Office of Basic Energy Sciences, of the U.S. Department of Energy under Contract No. DE-AC02-05CH11231. The work performed at PSI and SLS was carried out in the framework of the Swiss Competence Center for Energy Research (SCCER). Technical support by T. Gloor and M. Hottiger (both PSI) is gratefully acknowledged. 


\section{References}

1. Weber, A. Z.; Newman, J., Coupled Thermal and Water Management in Polymer Electrolyte Fuel Cells. J Electrochem Soc 2006, 153, A2205.

2. Oszcipok, M.; Riemann, D.; Kronenwett, U.; Kreideweis, M.; Zedda, M., Statistic Analysis of Operational Influences on the Cold Start Behaviour of Pem Fuel Cells. J. Power Sources 2005, 145, 407-415.

3. Mehta, V.; Cooper, J. S., Review and Analysis of Pem Fuel Cell Design and Manufacturing. J. Power Sources 2003, 114, 32-53.

4. Wang, Y.; Chen, K. S.; Mishler, J.; Cho, S. C.; Adroher, X. C., A Review of Polymer Electrolyte Membrane Fuel Cells: Technology, Applications, and Needs on Fundamental Research. Appl. Energy 2011, 88, 981-1007.

5. Weber, A. Z. Fuel Cell Fundamentals at Low and Subzero Temperatures 2014 DOE Hydrogen Program Annual Merit Reviews 2014.

6. Wang, Y.; Wang, C.-Y., A Nonisothermal, Two-Phase Model for Polymer Electrolyte Fuel Cells. J Electrochem Soc 2006, 153, A1193-A1200.

7. Kim, S.; Mench, M. M., Investigation of Temperature-Driven Water Transport in Polymer Electrolyte Fuel Cell: Phase-Change-Induced Flow. J Electrochem Soc 2009, 156, B353-B362.

8. Sinha, P. K.; Mukherjee, P. P.; Wang, C.-Y., Impact of Gdl Structure and Wettability on Water Management in Polymer Electrolyte Fuel Cells. J. Mater. Chem. 2007, 17, 3089-3103.

9. Rashapov, R. R.; Unno, J.; Gostick, J. T., Characterization of Pemfc Gas Diffusion Layer Porosity. J Electrochem Soc 2015, 162, F603-F612. 
10. Zenyuk, I. V.; Parkinson, D. Y.; Connolly, L. G.; Weber, A. Z., Gas-Diffusion-Layer Structural Properties under Compression Via X-Ray Tomography. J. Power Sources 2016, 328, 364-376.

11. Gostick, J. T.; Ioannidis, M. A.; Fowler, M. W.; Pritzker, M. D., Characterization of the Capillary Properties of Gas Diffusion Media. In Modern Aspects of Electrochemistry, Wang, C. Y.; Pasaogullari, U., Eds. Springer: Berlin, 2010; Vol. 49.

12. Owejan, J. P.; Trabold, T. A.; Mench, M. M., Oxygen Transport Resistance Correlated to Liquid Water Saturation in the Gas Diffusion Layer of Pem Fuel Cells. Int. J. Heat Mass Transfer 2014, 71, 585-592.

13. Weber, A. Z., et al., A Critical Review of Modeling Transport Phenomena in PolymerElectrolyte Fuel Cells. J Electrochem Soc 2014, 161, F1254-F1299.

14. Zenyuk, I. V.; Parkinson, D. Y.; Hwang, G.; Weber, A. Z., Probing Water Distribution in Compressed Fuel-Cell Gas-Diffusion Layers Using X-Ray Computed Tomography. Electrochem. Commun. 2015, 53, 24-28.

15. Zenyuk, I. V.; Taspinar, R.; Kalidindi, A. R.; Kumbur, E. C.; Litster, S., Computational and Experimental Analysis of Water Transport at Component Interfaces in Polymer Electrolyte Fuel Cells. J Electrochem Soc 2014, 161, F3091-F3103.

16. Becker, J. r.; Flückiger, R.; Reum, M.; Büchi, F. N.; Marone, F.; Stampanoni, M., Determination of Material Properties of Gas Diffusion Layers: Experiments and Simulations Using Phase Contrast Tomographic Microscopy. J Electrochem Soc 2009, 156, B1175.

17. Buechi, F. N.; Flückiger, R.; Tehlar, D.; Marone, F.; Stampanoni, M., Determination of Liquid Water Distribution in Porous Transport Layers. ECS Trans. 2008, 16, 587-592. 
18. Eller, J.; Rosén, T.; Marone, F.; Stampanoni, M.; Wokaun, A.; Büchi, F. N., Progress in in Situ X-Ray Tomographic Microscopy of Liquid Water in Gas Diffusion Layers of Pefc. $J$ Electrochem Soc 2011, 158, B963.

19. Rosen, T.; Eller, J.; Kang, J.; Prasianakis, N. I.; Mantzaras, J.; Buchi, F. N., Saturation Dependent Effective Transport Properties of Pefc Gas Diffusion Layers. J Electrochem Soc 2012, 159, F536-F544.

20. Hartnig, C.; Manke, I.; Kuhn, R.; Kardjilov, N.; Banhart, J.; Lehnert, W., Cross-Sectional Insight in the Water Evolution and Transport in Polymer Electrolyte Fuel Cells. Appl. Phys. Lett. 2008, 92, 134106.

21. Krüger, P.; Markötter, H.; Haußmann, J.; Klages, M.; Arlt, T.; Banhart, J.; Hartnig, C.; Manke, I.; Scholta, J., Synchrotron X-Ray Tomography for Investigations of Water Distribution in Polymer Electrolyte Membrane Fuel Cells. J Power Sources 2011, 196, 5250-5255.

22. Manke, I.; Hartnig, C.; Grünerbel, M.; Lehnert, W.; Kardjilov, N.; Haibel, A.; Hilger, A.; Banhart, J.; Riesemeier, H., Investigation of Water Evolution and Transport in Fuel Cells with High Resolution Synchrotron X-Ray Radiography. Appl. Phys. Lett. 2007, 90, 174105.

23. Epting, W. K.; Litster, S., Microscale Measurements of Oxygen Concentration across the Thickness of Diffusion Media in Operating Polymer Electrolyte Fuel Cells. J Power Sources 2016, 306, 674-684.

24. Eller, J.; Roth, J.; Gaudenzi, R.; Irvine, S.; Marone, F.; Stampanoni, M.; Wokaun, A.; Büchi, F. N., Water Distribution in Gdl near Optimal Humidification. ECS Trans 2013, 50, 477486.

25. Zenyuk, I. V.; Medici, E.; Allen, J.; Weber, A. Z., Coupling Continuum and Pore-Network Models for Polymer-Electrolyte Fuel Cells. Int. J. Hydrogen Energy 2015, 40, 16831-16845 
26. Kim, S.; Mench, M. M., Physical Degradation of Membrane Electrode Assemblies Undergoing Freeze/Thaw Cycling: Micro-Structure Effects. J Power Sources 2007, 174, 206220.

27. Sinha, P. K.; Wang, C.-Y., Gas Purge in a Polymer Electrolyte Fuel Cell. J Electrochem Soc 2007, 154, B1158-B1166.

28. Tajiri, K.; Wang, C.-Y.; Tabuchi, Y., Water Removal from a Pefc During Gas Purge. Electrochim. Acta 2008, 53, 6337-6343.

29. Cho, K. T.; Mench, M. M., Fundamental Characterization of Evaporative Water Removal from Fuel Cell Diffusion Media. J Power Sources 2010, 195, 3858-3869.

30. Zenyuk, I. V.; Kumbur, E. C.; Litster, S., Deterministic Contact Mechanics Model Applied to Electrode Interfaces in Polymer Electrolyte Fuel Cells and Interfacial Water Accumulation. J Power Sources 2013, 241, 379-387.

31. Owejan, J. P.; Trabold, T. A.; Jacobson, D. L.; Arif, M.; Kandlikar, S. G., Effects of Flow Field and Diffusion Layer Properties on Water Accumulation in a Pem Fuel Cell. Int. J. Hydrogen Energy 2007, 32, 4489-4502.

32. Kim, S.; Ahn, B. K.; Mench, M. M., Physical Degradation of Membrane Electrode Assemblies Undergoing Freeze/Thaw Cycling: Diffusion Media Effects. J Power Sources 2008, 179, 140-146.

33. Mayrhuber, I.; Marone, F.; Stampanoni, M.; Schmidt, T. J.; Büchi, F. N., Fast X-Ray Tomographic Microscopy: Investigating Mechanisms of Performance Drop During Freeze Starts of Polymer Electrolyte Fuel Cells. ChemElectroChem 2015, 2, 1551-1559.

34. Cho, K. T.; Mench, M. M., Effect of Material Properties on Evaporative Water Removal from Polymer Electrolyte Fuel Cell Diffusion Media. J Power Sources 2010, 195, 6748-6757. 
35. Whitaker, S.; Chou, W. T. H., Drying Granular Porous Media - Theory and Experiment. Drying Technol. 1983, 1, 3-33.

36. Laurindo, J. B.; Prat, M., Numerical and Experimental Network Study of Evaporation in Capillary Porous Media. Phase Distributions. Chem. Eng. Sci. 1996, 51, 5171-5185.

37. Le Bray, Y.; Prat, M., Three-Dimensional Pore Network Simulation of Drying in Capillary Porous Media. Int. J. Heat Mass Transfer 1999, 42, 4207-4224.

38. Prat, M., Percolation Model of Drying under Isothermal Conditions in Porous Media. Int. J. Multiphase Flow 1993, 19, 691-704.

39. Prat, M., Isothermal Drying on Non-Hygroscopic Capillary-Porous Materials as an Invasion Percolation Process. Int. J. Multiphase Flow 1995, 21, 875-892.

40. Shahidzadeh-Bonn, N.; Azouni, A.; Coussot, P., Effect of Wetting Properties on the Kinetics of Drying of Porous Media. J. Phys.: Condens. Matter 2007, 19, 112101.

41. Eller, J.; Buchi, F. N., Polymer Electrolyte Fuel Cell Performance Degradation at Different Synchrotron Beam Intensities. J. Synchrotron Radiat. 2014, 21, 82-88.

42. Roth, J.; Eller, J.; Büchi, F. N., Effects of Synchrotron Radiation on Fuel Cell Materials. J Electrochem Soc 2012, 159, F449-F455.

43. Groso, A.; Abela, R.; Stampanoni, M., Implementation of a Fast Method for High Resolutionphase Contrast Tomography. Opt. Express 2006, 14, 8103-8110.

44. Marone, F.; Stampanoni, M., Regridding Reconstruction Algorithm for Real-Time Tomographic Imaging. J. Synchrotron Radiat 2012, 19, 1029-1037.

45. Lamibrac, A.; Roth, J.; Toulec, M.; Marone, F.; Stampanoni, M.; Büchi, F. N., Characterization of Liquid Water Saturation in Gas Diffusion Layers by X-Ray Tomographic Microscopy. J. Electrochem. Soc. 2016, 163, F202-F209. 
46. Geuzaine, C.; Remacle, J.-F., Gmsh: A 3-D Finite Element Mesh Generator with Built-in Pre- and Post-Processing Facilities. Int. J. Numer. Methods Engineering 2009, 79, 1309-1331.

47. Curtiss, C. F.; Bird, R. B., Multicomponent Diffusion. Ind Eng Chem Res 1999, 38, 25152522.

48. Bird, R. B.; Stewart, W. E.; Lightfoot, E. N., Transport Phenomena; John Wiley \& Sons: New York, 1960.

49. Balliet, R. J.; Newman, J., Cold Start of a Polymer-Electrolyte Fuel Cell I. Development of a Two-Dimensional Model. J Electrochem Soc 2011, 158, B927.

50. Hickner, M. A.; Siegel, N. P.; Chen, K. S.; McBrayer, D. N.; Hussey, D. S.; Jacobson, D. L.; Arif, M., Real-Time Imaging of Liquid Water in an Operating Proton Exchange Membrane Fuel Cell. J Electrochem Soc 2006, 153, A902-A908.

51. Kim, D.; Yang, H.; Kim, K.; Yun, T., Experimental Investigation of Evaporation and Drainage in Wettable and Water-Repellent Sands. Sustainability 2015, 7, 5648. 
TOC Graphic

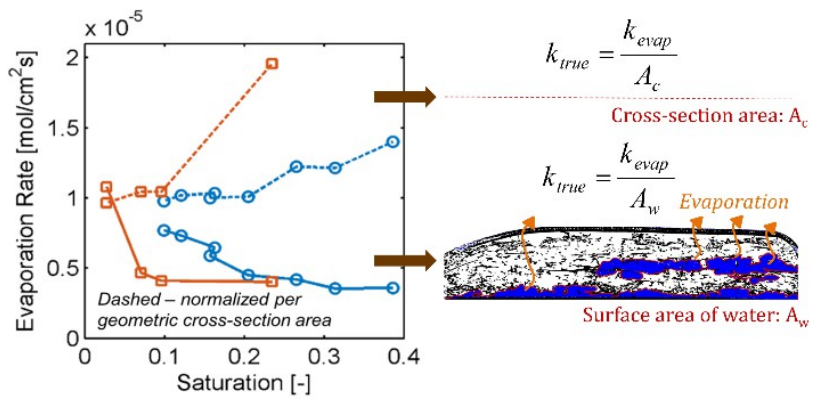

